\title{
From Playability to a Hierarchical Game Usability Model
}

\author{
Lennart Nacke \\ School of Computing \\ Blekinge Institute of Technology, Sweden \\ Lennart.Nacke@acm.org
}

\begin{abstract}
This paper presents a brief review of current game usability models. This leads to the conception of a high-level game development-centered usability model that integrates current usability approaches in game industry and game research.
\end{abstract}

\section{Categories and Subject Descriptors}

K.8.0 [General]: Games - Personal Computing. H.5.1 [Multimedia Information Systems]: Evaluation/methodology Information Interfaces and Presentation. J.4 [Computer Applications]: Psychology.

\section{General Terms}

Measurement, Design, Human Factors, Theory.

\section{Keywords}

game, usability, player experience, playability, model, theory.

\section{INTRODUCTION}

In recent years, we are seeing a lively debate about measures for usability and user experience in game contexts [1]. Admittedly, usability and playability may be dichotomous concepts [5, 7], but to understand how they relate to each other, we need to establish a basic taxonomical understanding of each term first.

Usability research generally operates within the ISO 9241-11 usability standard, which defines usability as the "extent to which a product can be used by specified users to achieve specified goals with effectiveness, efficiency, and satisfaction in a specified context of use" [4]. This conception of usability defines measurable factors. This led Sauro [11] to conclude that effectiveness can be measured in completion rates and errors, efficiency from time on task, and satisfaction using any of a number of standardized satisfaction questionnaires. This puts a numerical fundament under usability studies. Following this argumentation, one could see digital games merely as software with the same requirements on interaction as other products. However, experiencing gameplay does not equal experiencing regular product use. Thus, assuming that playability is related to measuring an experience, Fabricatore et al. find that "playability is the instantiation of the general concept of usability [...]

Permission to make digital or hard copies of all or part of this work for personal or classroom use is granted without fee provided that copies are not made or distributed for profit or commercial advantage and that copies bear this notice and the full citation on the first page. To copy otherwise, or republish, to post on servers or to redistribute to lists, requires prior specific permission and/or a fee.

FuturePlay@GDC Canada, May 12-13 2009, Vancouver, Canada. Copvright 2009 --- 1-XXXXX-XXX-0/00/0009...\$5.00. determined by [...] understanding and controlling gameplay" [3]. This could be interpreted to support a dichotomy of playability and usability, saying that playability is related only to a game's "capability to provide enjoyment for a player over an extended period of time" [7]. Since measurable factors of gameplay are being discovered for objective quantitative measurement $[8,9,13]$, these need to be incorporated in future playability definitions.

\section{MODELS OF PLAYABILITY}

Järvinen et al. [5] establish a definition of playability for both design and evaluation: "a collection of criteria with which to evaluate a product's gameplay or interaction". They proceed to introduce four components of playability derived from their take on flow in games [12]: (1) functional, (2) structural, (3) audiovisual, and (4) social playability, which are then analyzed in regard to formal aspects (game functional, e.g. rules) and informal aspects (user experience).

Functional playability maps input peripherals to requirements of gameplay, essentially referring to the learning curve of a game's input/output modalities. This relates to efficiency in the standard usability definition [4], but refers to interaction functionalities in game context. Structural playability is an expert evaluation of game rules, structures and patterns as well as player evaluation of skill, experience, and actions. This can be compared to usability heuristics evaluation of products [10]. Audiovisual playability refers to the quality of the visualization and sonification of game elements. It is naturally tied to functional playability as interface aspects can directly relate to input controls and feedback of the game. Social playability estimates the suitability of digital games for different contexts of use, using a lens through which game cultures are examined that foster a sense of community. This aspect of playability can only be assessed using long-term anthropological or sociological studies. While those four components of playability present a general approach to evaluating game experience, only functional and audiovisual playability are concepts that can be quantified using metric evaluation methods. What this approach [5] lacks are concrete examples of empirically measurable criteria of playability.

Desurvire et al. [2] present four game heuristic categories: game play, game story, game mechanics, game usability. The first category (game play) is in line with the descriptions of Korhonen's gameplay [6] and Järvinen's structural playability [5]. Game story certainly looks at a game's narrative development (if existent). Game mechanics are interface and programming rules, together with game usability, they relate to 
Korhonen's notion of game usability [6] and Järvinen's functional and audiovisual playability [5]. Korhonen et al. [6] presented playability heuristics modules for game usability, mobility and gameplay. Their heuristics for game usability are in line with what Järvinen et al. [5] call functional and audiovisual playability evaluation. The gameplay heuristics relate to the structural content of a game, placing them in a similar category as structural playability [5].

\section{A GAME USABILITY MODEL}

Most models acknowledge that usability is a fundament of playability, which leads us to propose the following model.

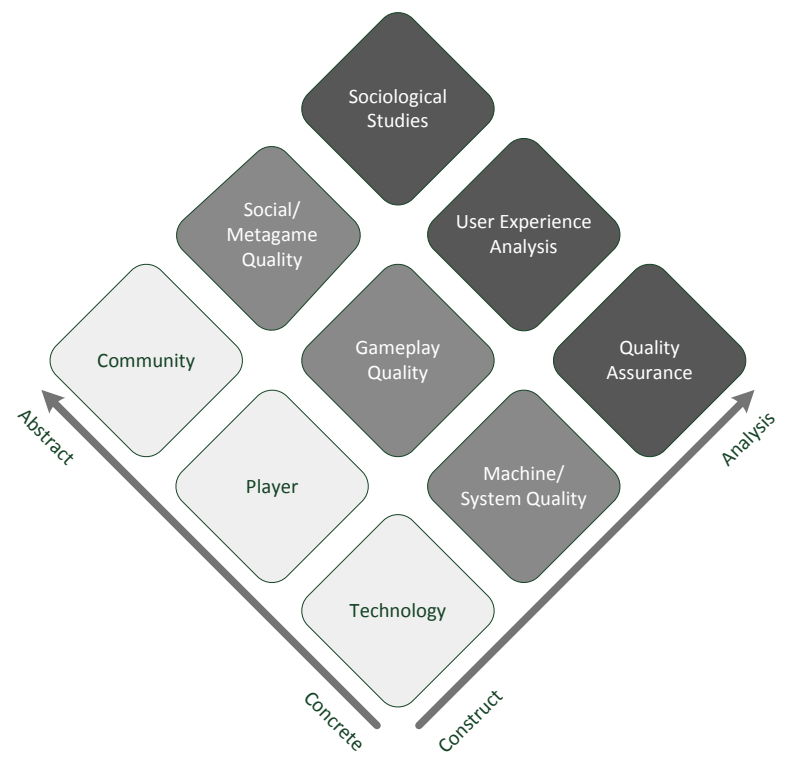

Figure 1. A hierarchical model of game usability

Figure 1 shows a hierarchical game usability model that accounts for concrete to abstract, measurable entities, which are described from theoretical construct to practical application. Working technology is the foundation of any digital game and it refers to the quality of the system. Quality assurance for it can be done using industry standard playtesting and bug tracking. In any way it refers to numerical evaluations of technological functionality, incorporating functional playability and game usability notions $[2,5,6]$. The level of abstraction is playerfocused evaluation, which assesses the gameplay experience using subjective and objective measures $[8,9]$. It can be placed in the context of gameplay and structural playability evaluation $[2,5,6]$. Finally, we have to take into account reception and cultural significance of a game, which can also be measured abstractly using anthropological and sociological approaches. This correlates with social playability and is something that is usually rather done in research than in industry context. We will continue to expand this model in future research, aiming to exemplify its applicability to all phases of game development.

\section{ACKNOWLEDGMENTS}

This research was funded by the European Commission under the 6th Framework Programme: NEST: FUGA (Contract: FP6NEST-28765).

\section{REFERENCES}

[1] Bernhaupt, R., Ijsselsteijn, W., Mueller, F. F., Tscheligi, M. and Wixon, D. Evaluating User Experiences in Games. In CHI '08 extended abstracts on Human factors in computing systems (Florence, Italy). ACM, 2008, 3905-3908. DOI = 10.1145/1358628.1358953.

[2] Desurvire, H., Caplan, M. and Toth, J. A. Using Heuristics to Evaluate the Playability of Games. In $\mathrm{CHI}$ '04 extended abstracts on Human factors in computing systems (Vienna, Austria). ACM, 2004, 1509-1512. DOI = 10.1145/985921.986102.

[3] Fabricatore, C., Nussbaum, M. and Rosas, R. Playability in Video Games: A Qualitative Design Model. HumanComputer Interaction, 17, 4 (2002), 311-368. DOI = 10.1207/S15327051HCI1704_1.

[4] ISO/IEC 9241-11 Ergonomic Requirements for Office Work with Visual Display Terminals (Vdts) -- Part 11: Guidance on Usability. ISO, 1998.

[5] Järvinen, A., Heliö, S. and Mäyrä, F. Communication and Community in Digital Entertainment Services. Prestudy Research Report, Hypermedia Laboratory, University of Tampere, Tampere, 2002. Retrieved on 2009-02-09 from http://tampub.uta.fi/tup/951-44-5432-4.pdf.

[6] Korhonen, H. and Koivisto, E. M. I. Playability Heuristics for Mobile Games. In Proceedings of the 8th conference on Human-computer interaction with mobile devices and services (Helsinki, Finland). ACM, 2006, 9-16. DOI = 10.1145/1152215.1152218.

[7] Kücklich, J. Play and Playability as Key Concepts in New Media Studies. STem Centre, Dublin City University, Dublin, 2004. Retrieved on 2009-02-09 from http://www.playability.de/Play.pdf.

[8] Mandryk, R. L., Inkpen, K. M. and Calvert, T. W. Using Psychophysiological Techniques to Measure User Experience with Entertainment Technologies. Behaviour \& Information Technology, 25, 2 (2006), 141-158. DOI = $10.1080 / 01449290500331156$.

[9] Nacke, L. and Lindley, C. A. Flow and Immersion in FirstPerson Shooters: Measuring the Player's Gameplay Experience. In Proceedings of the 2008 Conference on Future Play: Research, Play, Share (Toronto, Canada, November 3-5, 2008). ACM, 2008, 81-88. DOI = 10.1145/1496984.1496998.

[10] Nielsen, J. Usability Engineering. Morgan Kaufmann, 1993.

[11] Sauro, J. and Kindlund, E. A Method to Standardize Usability Metrics into a Single Score. In Proceedings of the SIGCHI conference on Human factors in computing systems (Portland, Oregon, USA ). ACM, 2005, 401 - 409. DOI = 10.1145/1054972.1055028.

[12] Sweetser, P. and Wyeth, P. Gameflow: A Model for Evaluating Player Enjoyment in Games. Computers in Entertainment (CIE), 3, 3 (2005), 3-3. DOI = 10.1145/1077246.1077253.

[13] Tychsen, A. and Canossa, A. Defining Personas in Games Using Metrics. In 2008 Conference on Future Play: Research, Play, Share (Toronto, Ontario, Canada). ACM, 2008, 73-80. DOI = 10.1145/1496984.1496997. 